ZOOLOGIA 32 (6): 431-437, December 2015

http://dx.doi.org/10.1590/S1984-46702015000600001

\title{
How do males of Hypsiboas goianus (Hylidae: Anura) respond to conspecific acoustic stimuli?
}

\author{
Alessandro R. Morais ${ }^{1, *}$, Mariana N. Siqueira ${ }^{2} \&$ Rogério P. Bastos ${ }^{3}$ \\ 'Instituto Federal Goiano, Campus Rio Verde, Caixa postal 66, 75.901-970, Rio Verde, Goiás, Brazil. \\ 2Programa de Pós-Graduação em Ciências Ambientais, Universidade Federal de Goiás, Caixa postal 131, \\ 74001-970, Goiânia, Goiás, Brazil. \\ ${ }^{3}$ Departamento de Ecologia, Instituto de Ciências Biológicas, Universidade Federal de Goiás, Caixa postal 131, \\ 74001-970, Goiânia, Goiás, Brazil. \\ "Corresponding author. E-mail: alessandro.ribeiro.morais@gmail.com
}

\begin{abstract}
Acoustic communication plays an important role in the social behavior of anurans. Acoustic signals, which can be used in different contexts such as mate attraction and territory defense, may mediate social interactions among individuals. Herein, we used playback experiments to test whether males of Hypsiboas goianus (Lutz, 1968) change their vocal behavior in response to conspecific advertisement calls. Specifically, we used different field playback experiments in which we modified the time interval between advertisement calls to simulate males with distinct states of motivation (Sequence $A$ and $B$ ). We did not observe differences in the acoustic response of males of $H$. goianus between the two types of field playback experiments. On the other hand, we observed that $H$. goianus males reduce the dominant frequency of the advertisement call and increase the rate of aggressive calls in response to a conspecific competitor. Our results suggest that the acoustic plasticity observed in males of $H$. goianus represents an aggressive response that allows repelling conspecific individuals.
\end{abstract}

KEY WORDS. Anuran; aggressive behavior; Brazilian savanna; vocalizations.

Acoustic communication plays an important role in the social behavior of many animal species (BRAdBURY \& VeHRENCAMP 1998, GERHARDT \& HUBER 2002). This is particularly true for many species of anuran amphibians that form aggregations with the participation of several individuals during the breeding season (WeLLs 1977, Aichinger 1987). In this sense, acoustic communication, which can be used in different contexts such as mate attraction, territory defense and maintenance of inter-male distance (Wells 1977, 2007), may mediate social interactions among individuals.

In many anuran species, the reproductive success of males is associated with the acoustic signals emitted by them (ForESTER et al. 1989). Even though several factors can influence such acoustic signals in reproductive aggregations (Penna \& Solis 1998, RÖHR \& JUNCÁ 2013), the interference caused by conspecifics probably represents the main reproductive obstacle for a calling male (GREENField \& RAND 2000). In this situation, anuran males can alter their acoustic behavior as an aggressive response to conspecific individuals (WelLs 1988). This response represents an important mechanism that allows maximization of the reproductive success of males (Gerhardt \& Huber 2002), enabling them to repel conspecific rivals and also to attract females for mates (Bosch \& Márquez 1996, 2000).

In response to intra-sexual acoustic competition, anuran males may display different vocal behaviors as a mechanism of aggressive response (Wells 1988, Gerhardt \& Huber
2002). In this case, individuals increase the rate of repetition of their calls (Wells 1988, BASTOS et al. 2011), increase call duration (Wells 1988), reduce the dominant frequency of the call (BeE et al. 2000) or modify call timing in response to competitors (ReICHERT \& Gerhardt 2012). Hypsiboas goianus (Lutz, 1968) is a hylid that is restricted to the Cerrado domain, and may be found in the states of Goiás and Minas Gerais, as well as Distrito Federal (Frost 2015, VALdujo et al. 2012). Males vocalize in choruses on herbaceous plants, grasses and shrubs (GUIMARÃEs et al. 2001, Menin et al. 2004). Males are commonly nocturnal and may emit different types of vocalization such as advertisement, aggressive and release calls (Guimarães et al. 2001, Menin et al. 2004, Diss et al. 2014).

Herein, we studied the acoustic behavior of males of $H$. goianus in response to a simulated conspecific, and tested whether the time interval between the conspecific's advertisement calls influence the vocal behavior of the experimental males. Specifically, our intention was to simulate male calls with distinct states of motivation. To do that we altered the time interval between calls to simulate different calling behaviors. In this context, as an aggressive response to the simulated conspecific, we expected that males of $H$. goianus would alter their acoustic behavior in several ways, for instance: 1) alter the emission of advertisement calls to aggressive calls, 2) increase call duration and/or 3) decrease the time interval between calls. 


\section{MATERIAL AND METHODS}

We studied the vocal behavior of males of $H$. goianus in a rivulet at Floresta Nacional (Flona) de Silvânia (16³8'51"S, $48^{\circ} 38^{\prime} 51^{\prime \prime} \mathrm{W}$, ca. $900 \mathrm{~m}$ a.s.l.) in the municipality of Silvânia, state of Goiás, central Brazil. The main vegetation formation in the region is the Cerrado, a seasonal Neotropical savanna in which the rainy season occurs between October and March and the dry season from April to September. Between February 2012 and January 2013, we conducted field observations over 10 visits to the study site, totaling 50 hours of observation. We carried out field playback experiments between 19:00 and 00:00 $\mathrm{h}$, since this period corresponds to the peak activity of this species (A.R. Morais, unpub. data).

We conducted two types of field playback experiments with a repeated-measures design. To build both playback experiments, we used a natural advertisement call (Fig. 1) emitted by a male of $H$. goianus, and which had been previously recorded at Flona de Silvânia. Call duration, dominant frequency and pulse number of the advertisement calls were 369 ms, $3273 \mathrm{~Hz}$ and three pulses per call, respectively. The duration of the first, second and third pulses were $34 \mathrm{~ms}, 64 \mathrm{~ms}$, and $40 \mathrm{~ms}$, respectively. We chose this advertisement call randomly; therefore, it does not represent the exact average of this population. Each playback experiment was composed of three treatment periods (pre-playback, playback, and post-playback); each treatment period lasted two minutes.

During pre-playback and post-playback periods, males of $H$. goianus were not stimulated by conspecific calls, although the acoustic behavior of these males was recorded. In the playback period, we broadcasted a sequence of six advertisement calls/minute to the calling male (Figs. 2-3). In both playback experiments, we positioned the speaker about $50 \mathrm{~cm}$ from the calling male and the calls were broadcasted with sound pressure level of $75 \mathrm{~dB}$ SPL (Minipa digital decibelimeter; Type II; Time weighting = Fast; A-weighted). To broadcast the acoustic signals during the playback period we used a digital speaker with the following setting: Qaaq - QA-909A model; Output power $=3 \mathrm{~W} \times 2$; Frequency response $=100 \mathrm{~Hz}-18 \mathrm{kHz}$.

The playback period differed between the experiments. In both experiments, all temporal and spectral parameters of the advertisement call were constant, except the time interval between calls. We manipulated the intercall distance to simulate two different calling behaviors within the playback period (sequence A and B, Figs. 2-3). Therefore, our intention was to use the time interval between calls as an aggressiveness measure (REICHERT \& GERHARDT 2012), since we simulated males with different states of motivation.

In the first (Sequence A) playback experiment, we simulated a calling male first decreasing and then increasing the intercall distance. Specifically, during this playback experiment, we reduced the time interval between calls to simulate a male increasing its aggressiveness when interacting with a conspe- cific. For this, we stablished the following time intervals between advertisement calls (in seconds): 15, 7.5, 3.75, 1.875, $1.875,30,1.875,1.875,3.75,7.5$, and 15 (Fig. 2).

In the second (Sequence B) playback experiment, we simulated a calling male first increasing and then decreasing the intercall distance. In this playback experiment, our intention was to simulate a male that reducing its aggressiveness when interacting with a conspecific. For this playback experiment, we stablished the following time intervals between calls (in seconds): $1.875,1.875,3.75,7.5,15,30,15,7.5,3.75,1.875$, and 1.875 (Fig. 3).

We tested 12 males in each playback experiment, totaling 24 recorded individuals. We recorded the calls of the males with a MARANTZ PMD 660 recorder [ $44 \mathrm{kHz}$ and 16-bit resolution (wav file)] and a Sennheiser ME66 microphone approximately $50 \mathrm{~cm}$ from the calling frog. We measured the body length (snout-vent length $-\mathrm{SVL}$ ) of males to the nearest $0.05 \mathrm{~mm}$ with a caliper, and their mass to the nearest $0.01 \mathrm{~g}$ with digital scales. The air temperature was recorded with a digital thermo-hygrometer to the nearest $0.1^{\circ} \mathrm{C}$. After each recording, we marked all individuals through subcutaneous implants of alpha-numeric fluorescent tags that are visible under ultraviolet light.

We used Raven Pro 1.4 to analyze the temporal and spectral parameters of $H$. goianus calls. Frequency information was obtained through Fast Fourier Transformation (FFT) with 1,024 points width. We used the package R 2.15.1, Seewave 1.6.4 (Sueur et al. 2008) to obtain sound figures. We analyzed five advertisement calls and five aggressive calls of each recorded male, and measured the following acoustic parameters : call duration (s), pulse number (pulses/call), pulse duration (s), dominant frequency $(\mathrm{Hz})$, total repetition rate (advertisement and aggressive calls/min), advertisement repetition rate (calls/ $\mathrm{min})$ and aggressive repetition rate (calls/min). The bioacoustics terminology followed Gerhardt (1998), Gerhardt \& Huber (2002) and Wells (2007).

To compare the body mass and SVL of the recorded individuals between different playback experiments (sequence A vs. sequence B) we used Student's t-test. We used principal component analysis (PCA) to eliminate the correlated acoustic variables. In this sense, we computed a PCA for each type of call (e.g., advertisement and aggressive), and considered the two first axes of each PCA as response variables. This approach allowed us to reduce our data set (acoustic parameters) of eight to four response variables. Based on axes of the PCA, we calculated a two-way repeated measures of analysis of variance (ANOVA) to compare acoustic parameters of the advertisement call of $H$. goianus males between the playback experiments (sequence A vs. sequence B) and treatment periods (pre-playback, playback, and post-playback).

It was not possible to use the same statistic approach for aggressive calls, since few males emitted this vocalization during all treatment periods (pre-playback, playback and post-playback periods). Thus, based on the axes of the PCA, we performed 

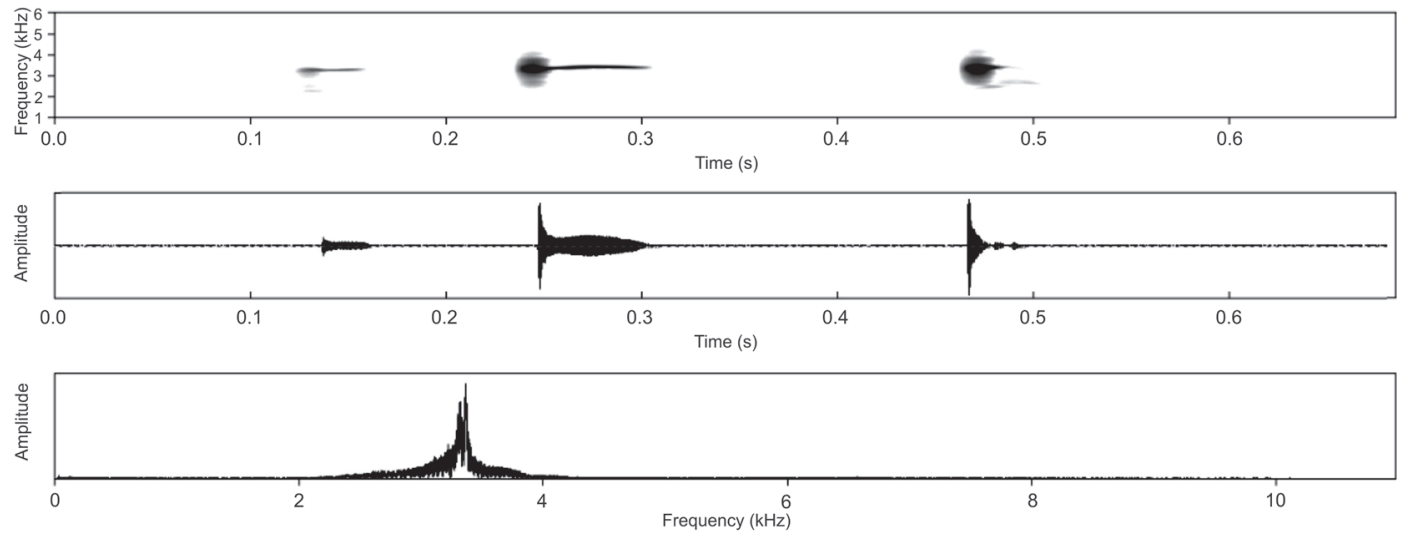

Figure 1. Spectrogram and oscillogram of the advertisement call of a male of Hypsiboas goianus recorded at Floresta Nacional de Silvânia, municipality of Silvânia, state of Goiás, Brazil. (Recording Marantz PMD660 and Sennheiser ME66 directional microphone; January 14, 2009; SVL $=28.91 \mathrm{~mm}$; mass $=1.2 \mathrm{~g}$; air temperature $=23.7^{\circ} \mathrm{C}$ ). Call used in both experiments (see text).

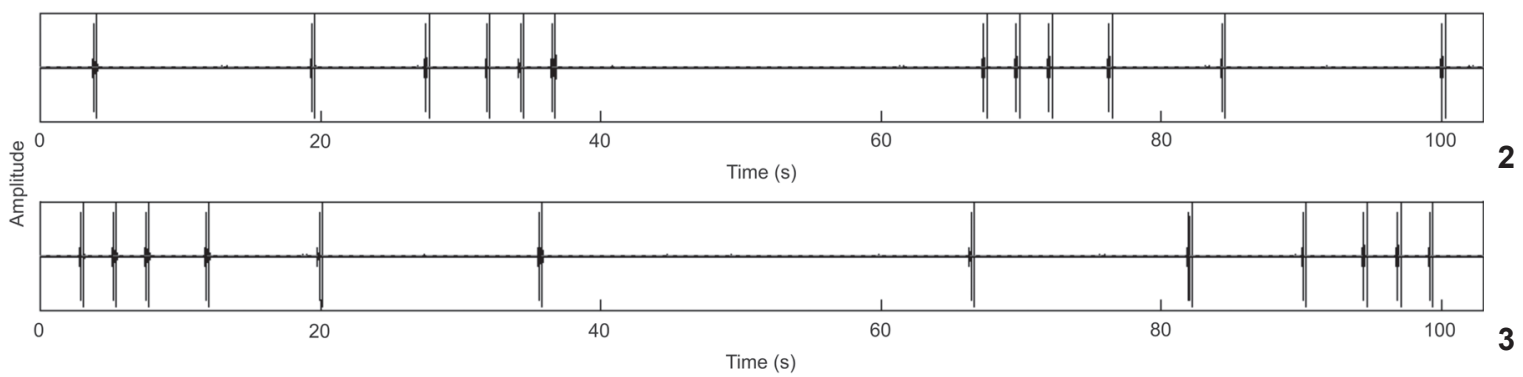

Figures 2-3. Design of the playback experiments conducted at the Floresta Nacional de Silvânia, municipality of Silvânia, state of Goiás, Brazil: (2) sequence A playback experiment; (3) sequence B playback experiment.

Student's t-test to compare the acoustic parameters of the aggressive call emitted during the playback period of both experiments (sequence A vs. sequence B). We computed a chi-square test to investigate whether the number of males that emitted aggressive calls differed among the treatment periods. We tested the assumptions of all statistical tests prior to analysis and, when necessary, the data were expressed logarithmically $[\log (\mathrm{x})]$ to reduce heterogeneity and non-normal distributions. The statistical analyses followed those described by ZAR (1996), and the significance level was 5\%.

\section{RESULTS}

The average SVL and body mass of all recorded males were $32.15 \pm 1.46 \mathrm{~mm}$ (range $=29.56-36.97 \mathrm{~mm}, \mathrm{~N}=24$ males) and $1.37 \pm 0.111 \mathrm{~g}$ (range $=1.2-1.62 \mathrm{~g}, \mathrm{~N}=24$ males), respectively. In the Sequence A playback experiment, the average SVL and body mass of males were $32.15 \pm 1.15 \mathrm{~mm}$ and $1.34 \pm 0.07$ $\mathrm{g}$, respectively, while in the Sequence B playback experiment the average SVL and body mass of males were $32.15 \pm 0.13 \mathrm{~mm}$ and $1.34 \pm 0.13 \mathrm{~g}$, respectively. We did not observe difference in the SVL $(\mathrm{t}=0.009, \mathrm{df}=22, \mathrm{p}>0.05)$ and body mass $(\mathrm{t}=1.63$, $\mathrm{df}=22, \mathrm{p}>0.05)$ of the recorded males between both field playback experiments.

Based on the computed PCA of the advertisement call, the two first axes had the following eigenvalues: 5429.30 (Axis 1) and 2474.35 (Axis 2). Together, these axes explained about $99 \%$ of all variation found. In this sense, axis 1 explained $68.31 \%$ of the variation and was positively associated with dominant frequency (Table 1); on the other hand, axis 2 explained $31.13 \%$ of the variation and was positively related with call duration (Table 1). For the aggressive call, the two first axes had the following eigenvalues: 19075.8 (Axis 1) and 4089.51 (Axis 2). Such axes explained $99.95 \%$ of the total variation found. The first axis was positively related to call duration and explained $82.3 \%$ of all variation (Table 1); while the second axis was positively related to dominant frequency and explained $17.6 \%$ of the total variation (Table 1 ).

We did not observe differences in the acoustic response of males of $H$. goianus between the two types of field playback experiments, because no axis of the computed PCA for the advertisement call ( $\mathrm{p}>0.05$ - two-way repeated measures analy- 
Table I. Factor loading of acoustic parameters of the advertisement and aggressive calls of Hypsiboas goianus included in the Principal Component Analysis.

\begin{tabular}{lcccccc}
\hline \multirow{2}{*}{ Acoustic parameters } & \multicolumn{2}{c}{ Advertisement call } & & \multicolumn{2}{c}{ Aggressive call } \\
\cline { 2 - 3 } \cline { 5 - 6 } & Axis 1 & Axis 2 & & Axis 1 & Axis 2 \\
\hline Call duration & 0.6302 & $0.7759^{*}$ & & $0.9861^{*}$ & -0.1646 \\
Pulse number & 0.002821 & 0.003441 & & 0.01302 & -0.00246 \\
Pulse duration & -0.00937 & -0.02821 & & 0.0156 & 0.000607 \\
Dominant frequency & $0.7764^{*}$ & -0.6302 & & 0.1646 & $0.9864^{*}$ \\
Eigenvalue & 5429.3 & 2474.35 & & 19075.8 & 4089.51 \\
\% variance & 68.311 & 31.132 & & 82.3 & 17.644 \\
\hline
\end{tabular}

* Represents the acoustic parameters more associated to each axis of the PCA.

ses of variance) and aggressive call ( $p>0.05$ - Student's t-test) varied significantly. However, we observed differences in the acoustic behavior of males of $H$. goianus during the three treatment periods of the playback experiments, since the axis 1 of the computed PCA for the advertisement call $\left(\mathrm{F}_{(2,32)}=3.623\right.$, $\mathrm{p}<0.05)$ varied significantly among such treatment periods (Fig. 4). This axis was largely represented by the dominant frequency of the advertisement call; therefore, we observed that such acoustic parameter was lower during the playback period than during the pre-playback and post-playback periods. For the other variables, we did not observe any difference among the three treatment periods ( $\mathrm{p}>0.05$ for all cases).

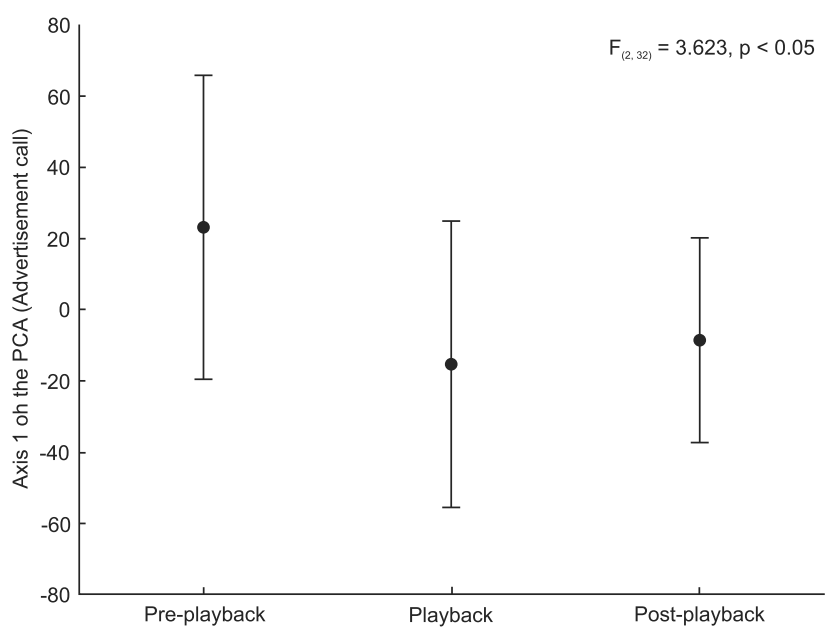

Figure 4. Results of the two-way repeated measures of analysis of variance (ANOVA) computed for axis 1 of the PCA performed to advertisement call of $H$. goianus males. ${ }^{*}$ Tukey's test $(p<0.001)$.

We observed that 10 and six males of $H$. goianus emitted advertisement and aggressive calls during all treatment periods of the Sequence A playback experiment, respectively (Table
2). On the other hand, we observed that eight and two $H$. goianus males emitted advertisement and aggressive calls during all treatment periods of the Sequence B playback experiment, respectively (Table 2 ). We also observed that the number of males that emitted aggressive calls during the playback period of both experiments was more than those observed in the pre-playback and post-playback periods (Chi-square test, $\mathrm{p}<0.0001$, Table 2).

\section{DISCUSSION}

In this study, we did not observe any difference in the acoustic behavior of the males in the two field playback experiments. On the other hand, we observed that males of $H$. goianus significantly modified their vocal behavior in response to conspecific acoustic stimuli. Specifically, the males of this species reduced the dominant frequency of their advertisement call and increased their emission of aggressive calls when interacting with conspecific competitors. According to WeLLS \& SCHWARTZ (2007), vocal competition between conspecifics may result in considerable acoustic plasticity in anurans; therefore, the males can modify the acoustic parameters of their call to repel conspecific individuals (Wels 1988).

Overall, the spectral parameters (e.g., dominant frequency) of the calls are under morphological constraints (RYAN 1986); therefore, they have been frequently classified as static proprieties, since they present low intra-individual coefficient (Gerhardt 1991, Bee et al. 2001, Gasser et al. 2009, Morais et al. 2012). However, as observed in H. goianus, some anuran species also reduce the frequency of their calls in response to conspecific individuals (Wells 1988, Wagner 1989b, Bee et al. 2000, Bee \& Bowling 2002, Nali \& Prado 2014). Specifically, Wagner (1989b) broadcasted conspecific calls to males of Acris crepitans Baird, 1854 and observed that the individuals reduced the dominant frequency of their call in response to a simulated opponent. Similarly, BeE et al. (2000) observed that small males of Lithobates clamitans (Latreille, 1801) significantly produced lower frequency calls in response to stimuli from large-looking males, which increase their apparent size during conspecific interactions. Changes in the dominant frequency of the call have an important role during aggressive interactions (Wells 2007, Wells \& Schwartz 2007); in this sense, we suggest that the modifications observed in the dominant frequency of the call of $H$. goianus indicate an aggressive function and, therefore, allow repelling the conspecific opponent.

Additionally, we observed that $H$. goianus males increased the rate of their aggressive call during playback periods. This aspect has been observed in other anuran species since WeLLS \& SChWARTz (1984) observed that males of Dendropsophus ebraccatus (Cope, 1874) emitted significantly more aggressive calls when stimulated by conspecific individuals. Similarly, males of Dendropsophus phlebodes (Stejneger, 1906) and Dendropsophus microcephalus (Cope, 1886) also increased the 
Table II. Number of calls emitted by H. goianus males during field playback experiments (sequences A and B), Floresta Nacional de Silvânia, municipality of Silvânia, state of Goiás, Brazil.

\begin{tabular}{|c|c|c|c|c|c|c|c|c|c|}
\hline & \multicolumn{3}{|c|}{ Total rate } & \multicolumn{3}{|c|}{ Advertisement call rate } & \multicolumn{3}{|c|}{ Short aggressive call rate } \\
\hline & Pre-playback & Playback & Post-playback & Pre-playback & Playback & Post-playback & Pre-playback & Playback & Post-playback \\
\hline \multicolumn{10}{|l|}{ Sequence $\mathrm{A}$} \\
\hline Male 1 & 4 & 4.5 & 0 & 4 & 0.0 & 0 & 0 & 4.5 & 0 \\
\hline Male 2 & 10 & 5.5 & 8 & 5 & 1.5 & 6 & 5 & 4.0 & 2 \\
\hline Male 3 & 9 & 5.5 & 13 & 5 & 2.0 & 4 & 4 & 3.5 & 9 \\
\hline Male 4 & 3 & 4.5 & 2 & 0 & 1.0 & 0 & 3 & 3.5 & 2 \\
\hline Male 5 & 13 & 8.5 & 14 & 6 & 4.5 & 6 & 7 & 4.0 & 8 \\
\hline Male 6 & 14 & 7.5 & 15 & 6 & 1.5 & 5 & 8 & 6.0 & 10 \\
\hline Male 7 & 10 & 11.5 & 21 & 9 & 4.0 & 5 & 1 & 7.5 & 16 \\
\hline Male 8 & 7 & 7.5 & 7 & 7 & 3.0 & 6 & 0 & 4.5 & 1 \\
\hline Male 9 & 9 & 12.5 & 15 & 9 & 1.5 & 5 & 0 & 11.0 & 0 \\
\hline Male 10 & 5 & 13.5 & 7 & 5 & 7.5 & 7 & 0 & 6.0 & 6 \\
\hline Male 11 & 17 & 7.5 & 9 & 5 & 0.5 & 3 & 12 & 7.0 & 0 \\
\hline Male 12 & 7 & 4.0 & 6 & 7 & 4.0 & 6 & 0 & 11.0 & 8 \\
\hline \multicolumn{10}{|l|}{ Sequence B } \\
\hline Male 1 & 17 & 11.0 & 13 & 5 & 0.0 & 5 & 12 & 11.0 & 8 \\
\hline Male 2 & 3 & 7.0 & 9 & 3 & 0.0 & 2 & 0 & 7.0 & 7 \\
\hline Male 3 & 1 & 0.0 & 4 & 1 & 0.0 & 4 & 0 & 0.0 & 0 \\
\hline Male 4 & 3 & 3.5 & 7 & 3 & 0.5 & 1 & 0 & 3.0 & 6 \\
\hline Male 5 & 2 & 7.0 & 8 & 2 & 2.0 & 5 & 0 & 5.0 & 3 \\
\hline Male 6 & 1 & 5.0 & 11 & 1 & 1.0 & 2 & 0 & 4.0 & 9 \\
\hline Male 7 & 11 & 10 & 10 & 11 & 3.0 & 10 & 0 & 7.0 & 0 \\
\hline Male 8 & 2 & 1.0 & 6 & 2 & 1.0 & 6 & 0 & 0.0 & 0 \\
\hline Male 9 & 8 & 5.5 & 5 & 5 & 3.0 & 5 & 3 & 2.5 & 0 \\
\hline Male 10 & 14 & 5.0 & 0 & 6 & 0.0 & 0 & 8 & 5.0 & 0 \\
\hline Male 11 & 6 & 2.0 & 1 & 5 & 2.0 & 1 & 1 & 0.0 & 1 \\
\hline Male 12 & 8 & 10.0 & 7 & 5 & 2.0 & 4 & 3 & 8.0 & 3 \\
\hline
\end{tabular}

rate of their aggressive call in response to conspecific calls (Wells 1988). According to TaIgen \& Wells (1985), the calling activity of anurans is one of their most energetically expensive activities; several studies have demonstrated that males emitting more calls per minute are more attractive to females (e.g., Bosch \& Márquez 2005, Poole \& Murphy 2007, Márquez et al. 2001). In this context, males that are able to maintain high call rates have higher energetic costs and therefore are in better physical shape (Poole \& MurPhy 2007) to obtain the female's preference. Additionally, high rates are easier to detect and to locate, and therefore they decrease the energetic cost and predation risk for the female to find a mate (Wells 2007).

Although $H$. goianus males increased the aggressive call rate during the playback period of the experiments, they continued to emit advertisement call while interacting with conspecifics. A similar pattern has been found in other anuran species such as A. crepitans (Wagner 1989a), Hypsiboas albomarginatus (Spix, 1824) (GIASSON \& HADDAD 2006), Leptopelis viridis (Günther, 1869) (GRAFE et al. 2000) and Scinax centralis Pombal \& Bastos, 1996 (BAstos et al. 2011). As previously shown by Gerhardt \& Huber (2002) and Wells (2007), aggressive calls are less attractive to reproductive mates than advertisement calls. In this sense, we suggest that males the H. goianus continue to emit advertisement calls, because this is the most important signal to attract reproductive mates and, additionally, it is useful to mediate spacing between males. Males may therefore alternate the emission of both calls to reduce the costs of acoustic interactions, since they may simultaneously repel conspecific individuals and attract females (WAGNER 1989a).

Finally, our results demonstrated that males of $H$. goianus may modify their acoustic behavior when interacting with conspecific individuals. In this sense, we considered the calling behavior of males of $\mathrm{H}$. goianus to understand the role of the acoustic parameters of calls during the aggressive interac- 
tions. Few studies have investigated the influence of conspecific calls in the acoustic behavior of anuran species in the Brazilian savannah (e.g., BASTOS et al. 2011, NALI \& PRADO 2014). In this domain, anuran species are under high anthropogenic pressure, therefore, the results described in this study can be useful in future management actions.

\section{ACKNOWLEDGEMENTS}

We acknowledge Mirco Solé, Natan M. Maciel, Fausto Nomura, Fábio Hepp, Rodrigo Lingnau and two anonymous referees for critical reading and valuables comments on the manuscript. R.P. Bastos (process 304363/2010-3) and M.N. Siqueira are greatful to Conselho Nacional de Desenvolvimento Científico e Tecnológico (CNPq), and A.R. Morais to Coordenação de Aperfeiçoamento de Pessoal de Nível Superior for fellowships. We acknowledge CNPq (process 476800/2011-0), Instituto Chico Mendes de Conservação da Biodiversidade, Fundação de Apoio à Pesquisa/UFG, and Programa de Apoio à Produtividade em Pesquisa - IF Goiano for financial and logistical support.

\section{LITERATURE CITED}

Aichinger M (1987) Annual activity patterns of anurans in a seasonal neotropical environment. Oecologia 71(4): 583592. doi: 10.1007/BF00379302

Bastos RP, Alcantara MB, Morais AR, Lingnau R, Signorelli L (2011) Vocal behavior and conspecific call response in Scinax centralis (Anura: Hylidae). Herpetological Journal 21(1): 43-50.

Bee MA, Bowling AC (2002) Socially mediated pitch alteration by territorial male bullfrogs, Rana catesbeiana. Journal of Herpetology 36(1): 140-143. doi: 10.2307/1565821

Bee MA, Perrill SA, Owen PC (2000) Male green frogs lower the pitch of acoustic signals in defense of territories: a possible dishonest signal of size? Behavioral Ecology 11(2): 169177. doi: 10.1093/beheco/11.2.169

Bee MA, Kozich CE, Blackwell KJ, Gerhardt HC (2001) Individual variation in advertisement calls of territorial male green frog, Rana clamitans: Implications for individual discrimination. Ethology 107(1): 65-84. doi: 10.1046/j.1439-0310.2001.00640.x

Bosch J, Márquez R (1996) Acoustic competition in male midwife toads Alytes obstetricans and Alytes cisternasii: Response to neighbor size and calling rate. Implications for female choice. Ethology 102(6): 841-855. doi: 10.1111/j.14390310.1996.tb01205.x

Bosch J, Márquez, R (2000) Acoustical interference in the advertisement calls of the midwife toads (Alytes obstetricians and Alytes cisternasii). Behaviour 137(2): 249-263. doi: $10.1163 / 156853900502060$

Bosch J, Márquez R (2005) Female preference intensities on different call characteristics and symmetry of preference above and below the mean in Alytes. Ethology 111(3): 323333. doi: 10.1111/j.1439-0310.2004.01058.x

Bradbury JW, Vehrencamp SL (1998) Principles of Animal Communication. Massachusetts, Sinauer, 697p.

Dias TM, Bastos, RP, Siqueira MN, Morais AR (2014) The release call of Hypsiboas goianus (B. Lutz, 1968) (Anura: Hylidae) from Central Brazil. Herpetology Notes 7(1): 215-217.

Forester DC, LyKens DV, Harrison K (1989) The significance of persistent vocalization by the spring peeper Pseudacris crucifer (Anura: Hylidae). Behaviour 108(3): 197-208. doi: 10.1163/156853989x00303

Frost DR (2015) Amphibian species of the world: an online reference. New York, American Museum of Natural History, version 6.0. Available online at: http://research.amnh.org/ vz/herpetology/amphibia [Accessed: 10/10/2015]

Gasser H, Amézquita A, Hödl W (2009) Who is calling? Intraspecific call variation in the Aromobatid Frog Allobates femoralis. Ethology 115(6): 596-607. doi: 10.1111/j.14390310.2009.01639.x

Gerhardt HC (1991) Female mate choice in treefrogs: static and dynamic acoustic criteria. Animal Behaviour 42(4): 615635. doi: 10.1016/S0003-3472(05)80245-3

GERHARDT HC (1998) Acoustic signals of animals: recording, field measurements, analysis and description, p. 1-25. In: Hopp SL, OWRen MJ, Evans CS (Eds.). Animal acoustic communication. Berlim, Springer Verlarg, 421p.

Gerhardt HC, Huber F (2002) Acoustic Communication in insects and Anurans: common problems and diverse solution. Chicago, University of Chicago Press, 542p.

Giasson LOM, Haddad CFB (2006) Social interactions in Hypsiboas albomarginatus (Anura: Hylidae) and the significance of acoustic and visual signals. Journal of Herpetology 40(2): 171-180. doi: 10.1670/205-05A.1

Grafe TU, Steffen JO, Stoll C (2000) Vocal repertoire and effect of advertisement call intensity on calling behavior in the West African tree frog, Leptopelis viridis. Amphibia-Reptilia 21(1): 13-23. doi: 10.1163/156853800507246

Greenfield MD, Rand AS (2000) Frogs have rules: selective attention algorithms regulate chorusing in Physalaemus pustulosus (Leptodactylidae). Ethology 106: 331-347. doi: 10.1046/j.1439-0310.2000.00525.x

Guimarães LD, Lima LP, Juliano RF, Bastos RP (2001) Vocalizações de espécies de anuros (Amphibia) no Brasil Central. Boletim do Museu Nacional, Série Zoologia 474: 1-14.

Márquez R, Pargana JM, Crespo EG (2001) Acoustic competition in male Pelodytes ibericus (Anura: Pelodytidae): Interactive playback tests. Copeia 2001(4): 1142-1150. doi: 10.1643/ 0045-8511(2001)001[1142:ACIMPI]2.0.CO;2

Menin M, Silva RA, Giaretta AA (2004) Reproductive biology of Hyla goiana (Anura, Hylidae). Iheringia, Série Zoologia 94(1): 49-52. doi: 10.1590/S0073-47212004000100008

Morais AR, Batista VG, Gambale PG, Signorelli L, Bastos RP (2012) Acoustic communication in a Neotropical frog 
(Dendropsophus minutus): vocal repertoire, variability, and individual discrimination. Herpetological Journal 22(4): 249-257.

Nali RC, Prado CPA (2014) Complex call with diferente messages in Bokermannohyla ibitiguara (Anura, Hylidae), a gladiator frog of the Brazilian Cerrado. Journal of Herpetology 48(3): 407-414. doi: 10.1670/13-090

Penna M, Solís M (1998) Frog call intensities and sound propagation in the South American temperate forest region. Behavioral Ecology and Sociobiology 42(6): 371-381. doi: $10.1007 / \mathrm{s} 002650050452$

Poole KG, Murphy CG (2007) Preferences of females barking treefrogs, Hyla gratiosa, for larger males: univariate and composite tests. Animal Behaviour 73(3): 513-524. doi: 10.1016/j.anbehav.2006.09.008

ReICHert MS, Gerhardt HC (2012) Socially mediated plasticity in call timing in the gray tree frog, Hyla versicolor. Behavioral Ecology 23: 393-401. doi: 10.1093/beheco/ars176

RÖHR DL, JUnCÁ FA (2013) Micro-Habitat Influence on the Advertisement Call Structure and Sound Propagation Efficiency of Hypsiboas crepitans (Anura: Hylidae). Journal of Herpetology 47(4): 549-554. doi: 10.1670/10-210

RyAn MJ (1986) Factors influencing the evolution of acoustic communication: biological constraints. Brain, Behavior and Evolution 28(1-3): 70-82. doi: 10.1159/000118693

Sueur J, Aubin T, Simonis C (2008) Seewave, a free modular tool for sound analysis and synthesis. Bioacoustics 18(2): 213226. doi: 10.1080/09524622.2008.9753600

TAIGEN TL, Wells KD (1985) Energetics of vocalization by an anuran amphibian (Hyla versicolor). Journal of Comparative Physiology B 155(2): 163-170. doi: 10.1007/BF00685209
Valdujo PH, Silvano DL, Colli G, Martins M (2012) Anuran Species Composition and Distribution Patterns in Brazilian Cerrado, a Neotropical Hotspot. South American Journal of Herpetology 7(2): 63-78. doi: 10.2994/057.007.0209

WAGNER WE (1989a) Graded aggressive signals in Blanchard's cricket frog: vocal responses to opponent proximity and size. Animal Behaviour 38(6): 1025-1038. doi: 10.1016/ S0003-3472(89)80141-1

WAGNER WE (1989b) Fighting, assessment, and frequency alteration in Blanchard's cricket frog. Behavioral Ecology and Sociobiology 25(6): 429-436. doi: 10.1007/BF00300189

Wells KD (1977) The social behaviour of anuran amphibians. Animal Behaviour 25(3): 666-693. doi: 10.1016/00033472(77)90118-X

WeLLS KD (1988) The effect of social interactions on anuran vocal behavior, p. 433-454. In: Fritzsch B, RyAn M, WilczynsKi W, Walkowiak W, Hetherington T (Eds.) The Evolution of the Amphibian Auditory System. New York, John Wiley and Sons, 720p.

WeLLS KD (2007) The ecology and behavior of amphibians. Chicago, University of Chicago Press, 1400p.

Wells KD, Schwartz JJ (1984) Vocal communication in a neotropical treefrog, Hyla ebraccata: advertisement calls. Animal Behaviour 32(2): 405-420. doi: 10.1016/S00033472(84)80277-8

Wells KD, SchWARTZ JJ (2007) The behavioral ecology of anuran communication, p. 44-86. In: Narins PM, Feng AS, FAY RR, Popper AN (Eds.) Hearing and Sound Communication in Amphibians. New York, Springer, 366p.

ZAR JH (1996) Biostatistical Analysis. New Jersy, Prentice-Hall, 662 p.

Submitted: 14 April 2015

Received in revised form: 25 October 2015

Accepted: 1 November 2015

Editorial responsibility: Diego Astúa de Moraes 